\title{
PREPARATION, CHARACTERIZATION, AND THERMAL STABILITY OF $\mathrm{B}_{2} \mathrm{O}_{3}-\mathrm{SiO}_{2}$
}

\author{
Winda Fitriana ${ }^{1 *}$, Aldes Lesbani ${ }^{1}$ \\ ${ }^{1}$ Department of Chemistry, Faculty of Mathematic and Natural Science, Sriwijaya University \\ *Corresponding Author Email: winda.fitriana@rocketmail.com
}

\begin{abstract}
Preparation of $\mathrm{B}_{2} \mathrm{O}_{3}-\mathrm{SiO}_{2}$ compound by inorganic synthesis was carried out. $\mathrm{B}_{2} \mathrm{O}_{3}-\mathrm{SiO}_{2}$ was characterized by FT-IR spectrophotometer, analysis of crystallinity by XRD, and test of acidity. $\mathrm{B}_{2} \mathrm{O}_{3}-\mathrm{SiO}_{2}$ was also tested by thermal stability with temperature range at $300-700^{\circ} \mathrm{C}$. The results showed that the FT-IR spectrum of $\mathrm{B}_{2} \mathrm{O}_{3}-\mathrm{SiO}_{2}$ has some vibrations of $\mathrm{B}-\mathrm{O}$, Si-O-Si, Si-O-B stretching, and Si-O-B bending at $1442.8 \mathrm{~cm}^{-1}, 779.2 \mathrm{~cm}^{-1}, 925.8 \mathrm{~cm}^{-1}$, and $648.1 \mathrm{~cm}^{-1}$. The X-Ray diffraction pattern results showed that the analysis of $\mathrm{B}_{2} \mathrm{O}_{3}-\mathrm{SiO}_{2}$ has high crystallinity with two peaks diffraction identified at $26.6^{0}$ and $20.9^{\circ}$. The thermal stability test of $\mathrm{B}_{2} \mathrm{O}_{3}-\mathrm{SiO}_{2}$ showed that $\mathrm{B}_{2} \mathrm{O}_{3}-\mathrm{SiO}_{2}$ has high thermal stability with temperature range at $300-700{ }^{\circ} \mathrm{C}$. The results showed that the acidity analysis of $\mathrm{B}_{2} \mathrm{O}_{3}-\mathrm{SiO}_{2}$ has potential number $122.71 \mathrm{mV}$ so that indicated $\mathrm{B}_{2} \mathrm{O}_{3}-\mathrm{SiO}_{2}$ was high acidity.
\end{abstract}

Keywords : boric oxide, silica dioxide, boric silica, $\mathrm{B}_{2} \mathrm{O}_{3}-\mathrm{SiO}_{2}$

\section{INTRODUCTION}

The development of materials such as inorganic materials and hybrid organic inorganic materials is intriguing field as this decade due to applications of these materials for sensor, catalyst, ion exchange, membrane, and also for medical as drugs or agent transfer drugs. The development of these materials can be conducted using physical and chemical processes such as grafting (Chrouda et.al, 2015), sol-gel (McFarland and Opila, 2016), impregnation (Dhamodaran and Gnanaharan, 2007), support compound (Sari M A and Situngkir, 2016), and chemical reaction. In the chemical reaction, formation of chemical bonding is important in order to form stable novel compounds. Chemical reaction sometime involves high temperature and pressure thus this method is sometime omitted due to special reactor is required. In physical method such as impregnation and support method, electrostatic interaction, Van der Walls, or other physical interaction is formed on materials.

In recent years, support materials on inorganic matric is increased sharply. Inorganic substances such as boron compounds and its derivatives is interesting materials to develop due to high acidity resulted from non-bonding orbital of boron. Boron is found as various compounds in the nature such as boric acid and has been applied as catalyst (Kumar et.al, 2014). Boric acid has low thermal stability and the application of these compound in various field is still rare. To increase application of that compound thus modification of boric acid is vital. On the other sides, silica compounds such as silica oxide are frequently used in various application such as chromatography for separation and for polymer materials. Silica oxide can be used also as support material for inorganic matric (Jal, et.al 2004). Thus in this research silica oxide is used as support of boric

\section{Article History}

Received: 21 August 2016

Accepted: 30 November 2016

DOI: $10.26554 /$ sti.2017.2.1.22-24 compound. The final goal of this research is to obtain inorganic material with high acidity and stability under high temperature. High temperature stable material is needed for many applications such as catalyst and thin film (Moon et.al, 2004). The supported material is characterized using X-ray analysis, FTIR spectrophotometer, and acidity analysis by potentiometric titration.

\section{EXPERIMENTAL SECTION}

Chemical with p.a. grade was used in this research from Merck such as boric acid, silica dioxide, acetonitrile, nbutylamine, ammonia, and buffer $\mathrm{pH} 4,7$, and 10 . Characterization was conducted using Shimadzu FTIR Prestige21 with KBR disc, X-Ray Shimadzu Lab X type-6000 and the data was acquired over 0-90 deg. The acidity was analyzed by potentiometric titration using $\mathrm{n}$-butylamine.

\section{Preparation of $\mathrm{B}_{2} \mathrm{O}_{3}-\mathrm{SiO}_{2}$}

Boric acid $(0.16 \mathrm{~g})$ was dissolved with $30 \mathrm{~mL}$ water. The solution was stirring and heating at $80{ }^{\circ} \mathrm{C}$ for 10 minutes. Silica oxide $(1.46 \mathrm{~g})$ was added into the solution. The mixtures were refluxed for 5 hours at $90{ }^{\circ} \mathrm{C}$. The mixtures was concentrated by vacuum to obtain white bulky solid. The solid material was heated at $110{ }^{\circ} \mathrm{C}$ for three days to form $\mathrm{B}_{2} \mathrm{O}_{3}-\mathrm{SiO}_{2}$. Characterization of $\mathrm{B}_{2} \mathrm{O}_{3}-\mathrm{SiO}_{2}$ was conducted using FTIR and X-Ray analyses.

\section{Thermal Stability Test}

Thermal stability test was conducted using muffle furnace and sample was heated for 3 hours at $400-700{ }^{\circ} \mathrm{C}$. The material after heating process was analyzed by $\mathrm{X}$-Ray analysis and acidity measurement.

\section{RESULTS AND DISCUSSION}

Material $\mathrm{B}_{2} \mathrm{O}_{3}-\mathrm{SiO}_{2}$ was prepared via inorganic synthetic method without functional group protection. The objectives of this preparation is to obtain material with high acidity and high 
stability under high temperature. Material $\mathrm{B}_{2} \mathrm{O}_{3}-\mathrm{SiO}_{2}$ after synthesis was characterized using FTIR spectroscopy and FTIR spectrum is shown in Figure 1.

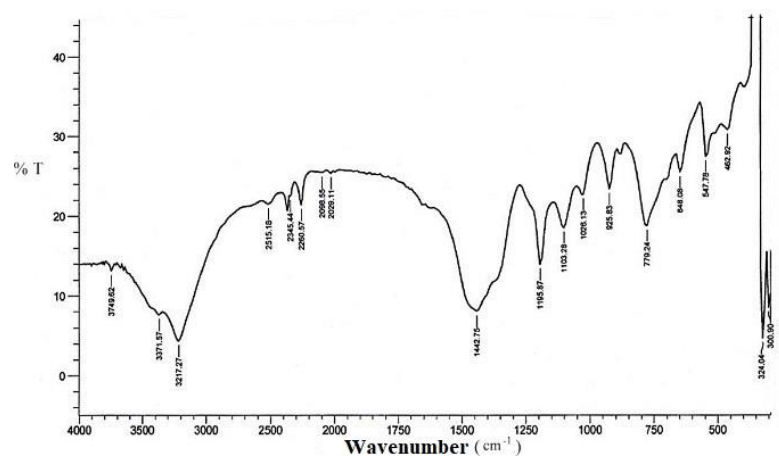

Figure 1. FTIR spectra of $\mathrm{B}_{2} \mathrm{O}_{3}-\mathrm{SiO}_{2}$.

FTIR spectrum of $\mathrm{B}_{2} \mathrm{O}_{3}-\mathrm{SiO}_{2}$ has vibration at wavenumber $3434 \mathrm{~cm}^{-1}(\mathrm{Si}-\mathrm{OH})$, and $3227 \mathrm{~cm}^{-1}(\mathrm{~B}-\mathrm{OH})$. Stretching vibration of Si-O-Si is appeared at wavenumber 1091-800 $\mathrm{cm}^{-1}$ (Arkles, 1987). Vibration peaks at $927 \mathrm{~cm}^{-1}$ and $649 \mathrm{~cm}^{-1}$ are assigned as bending and stretching of Si-O-B and $1435 \mathrm{~cm}^{-1}$ is assigned as stretching of $\mathrm{B}-\mathrm{O}$. Identification of $\mathrm{B}_{2} \mathrm{O}_{3}-\mathrm{SiO}_{2}$ is continued using X-ray analysis. The XRD powder pattern of $\mathrm{B}_{2} \mathrm{O}_{3}-\mathrm{SiO}_{2}$ is shown in Figure 2.

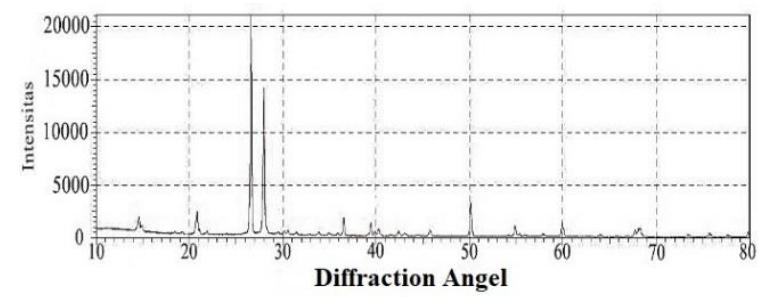

Figure 2. XRD powder pattern of $\mathrm{B}_{2} \mathrm{O}_{3}-\mathrm{SiO}_{2}$.

Compound $\mathrm{B}_{2} \mathrm{O}_{3}$ has diffraction at $2 \theta$ value $26-27 \mathrm{deg}$ and compound $\mathrm{SiO}_{2}$ has diffraction at $2 \theta$ value $20-22 \mathrm{deg}$. Figure 2 show the diffraction at $2 \theta$ value $20 \mathrm{deg}, 26 \mathrm{deg}$, and $29 \mathrm{deg}$, which is attributed to diffraction of $\mathrm{B}_{2} \mathrm{O}_{3}-\mathrm{SiO}_{2}$ (Osiglio et.al, 2017). There is small diffraction at $2 \theta$ value $15 \mathrm{deg}$. Probably do to interaction of $\mathrm{B}_{2} \mathrm{O}_{3}-\mathrm{SiO}_{2}$ and that diffraction indicated that material $\mathrm{B}_{2} \mathrm{O}_{3}-\mathrm{SiO}_{2}$ has high crystallinity. The properties of $\mathrm{B}_{2} \mathrm{O}_{3}-\mathrm{SiO}_{2}$ was studied by thermal stability test and acidity measurement.

The thermal stability test was conducted at 400-700 ${ }^{\circ} \mathrm{C}$ and the material was characterized using X-Ray analysis as shown in Figure 3. Diffraction patterns of XRD in Figure 3 showed that material $\mathrm{B}_{2} \mathrm{O}_{3}-\mathrm{SiO}_{2}$ has high stability under high temperature. The pattern is almost similar each other after heating process. The patterns in Figure 3 is also fit with pattern in Figure 2. That means structure material $\mathrm{B}_{2} \mathrm{O}_{3}-\mathrm{SiO}_{2}$ almost unchanged with increasing temperature.

The acidity material $\mathrm{B}_{2} \mathrm{O}_{3}-\mathrm{SiO}_{2}$ and boric acid was tested using potentiometric titration as shown in Figure 4. The titration curve at figure 4 showed that boric acid has potential $57.17 \mathrm{mV}$ and $\mathrm{B}_{2} \mathrm{O}_{3}-\mathrm{SiO}_{2}$ has potential $122.71 \mathrm{mV}$. That results showed that material $\mathrm{B}_{2} \mathrm{O}_{3}-\mathrm{SiO}_{2}$ has high acidity than boric acid. Thus material $\mathrm{B}_{2} \mathrm{O}_{3}-\mathrm{SiO}_{2}$ is candidate for acid catalyst material.

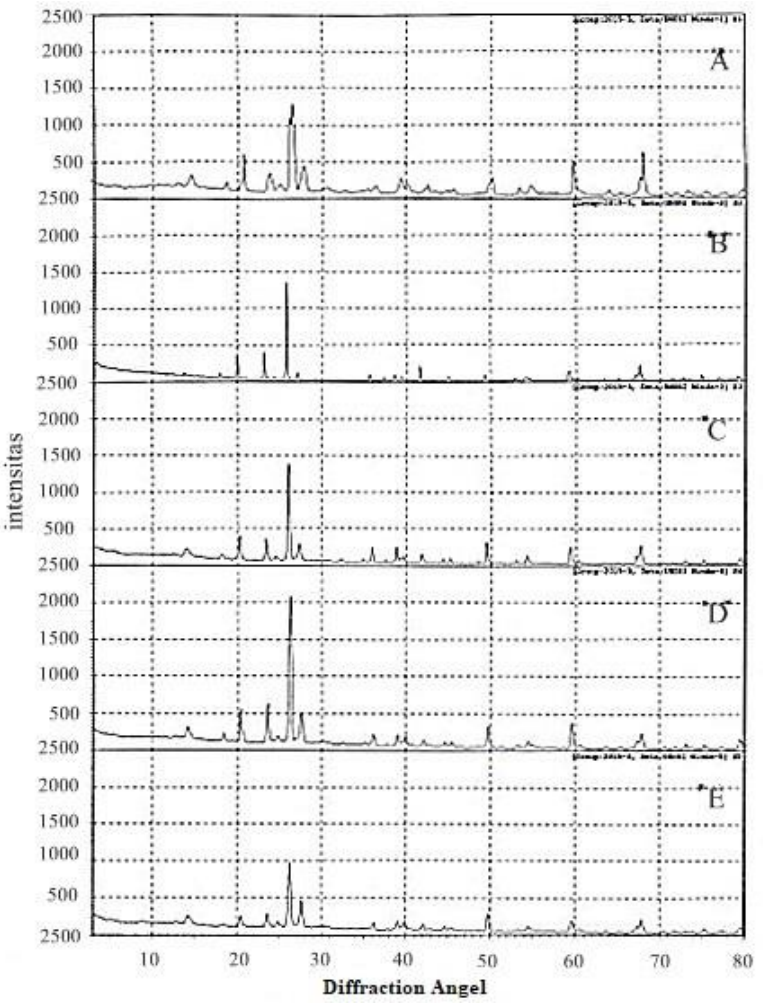

Figure 3. XRD powder patterns of $\mathrm{B}_{2} \mathrm{O}_{3}-\mathrm{SiO}_{2}$ at various temperatures $\left(\mathrm{A}=300{ }^{\circ} \mathrm{C}, \mathrm{B}=400{ }^{\circ} \mathrm{C}, \mathrm{C}=500^{\circ} \mathrm{C}, \mathrm{D}=600{ }^{\circ} \mathrm{C}\right.$, $\left.\mathrm{E}=700^{\circ} \mathrm{C}\right)$.
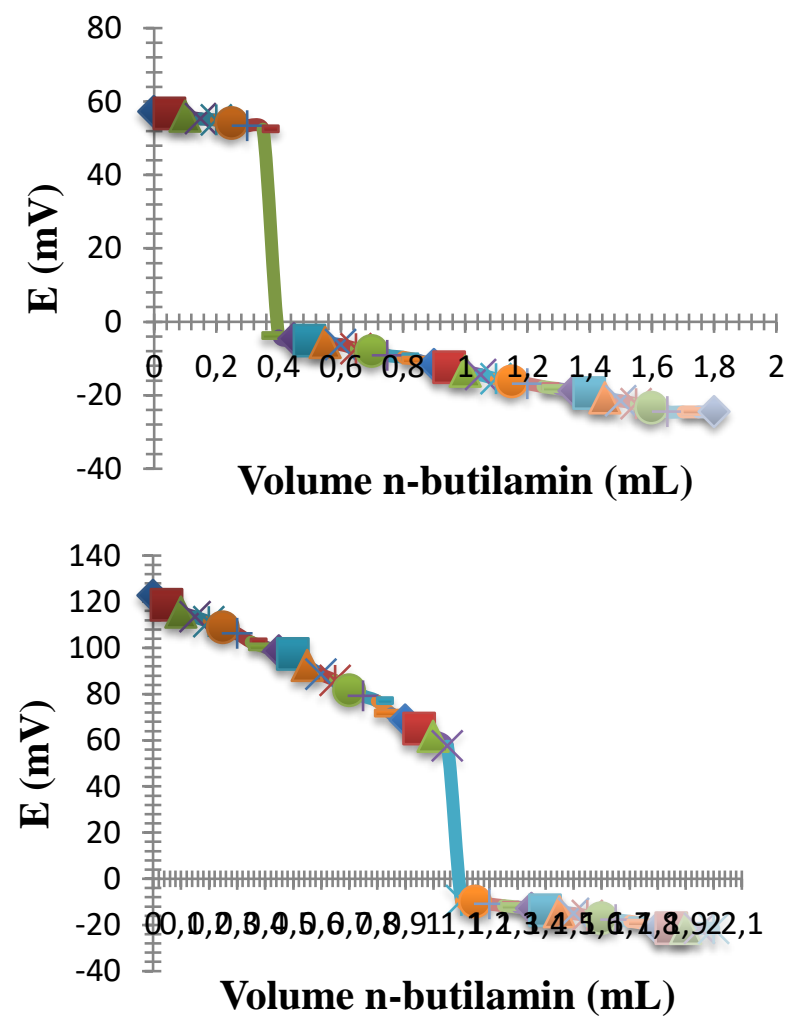

Figure 4. Potentiometric titration curve of boric acid (A) and $\mathrm{B}_{2} \mathrm{O}_{3}-\mathrm{SiO}_{2}(\mathrm{~B})$. 


\section{CONCLUSION}

Material $\mathrm{B}_{2} \mathrm{O}_{3}-\mathrm{SiO}_{2}$ was successfully synthesized with high crystallinity. This compound also has thermal stability and high Lewis acidity, which can be used as effective acid catalyst.

\section{REFERENCES}

Arkles, B. 1987. Infrared Analysis of Organosilicon Compounds : Spectra-Structure Correlations. Laboratory For Materials, Inc. Burnt Hills, New York.

Chrouda, A., Sbartai, A., Baraket, A., Renaud, L., Maaref, A., Jaffrezic-Renault, N. 2015. An Aptasensor for Ochratoxin a Based on Grafting of Polyethylene Glycol on Boron-Doped Diamond Microcell. Analytical Biocehemistry, 488, 36-44.

Dhamodaran, T.L., Gnanaharan, R. 2007. Boron Impregnation Treatment of Eucalyptus grandis Wood. Bioresource Technology, 98(11), 2240-2242.

Jal, P. K., S. Patel, and B. K. Mishra. 2004. Chemical Modification of Silica Surface by Immobilization of Functional Groups for Extractive Concentration of Metal Ions. Talanta, 62, 1005-1028.
Kumar, V., Chitra S., Upendra S., Praveen K. V., Bikram S., and Neeraj K. 2014. Silica-Supported Boric Acid Catalyzed Synthesis of Dihydropyrimidin-2-Ones, Bis(indolyl)methanes, Esters, and Amides. Indian Journal of Chemistry, 53, 1, 83-89.

McFarland, B., Opila, E.J. 2016. Sol-Gel Derived Borosilicate Glases and Thin Film Coatings on SiC Substances: Boron Loss and Carbon Retention duet Processing and Heat Treatment. Journal of Non-Crystalline Solids, 449, 59-69.

Moon, O. M., B. C. Kang, S. B. Lee, and J. H. Boo. 2004. Temperature Effect on Structural Properties of Boron Oxide Thin Film Deposited by MOCVD Method. Thin Solid Films, 164-169.

Osiglio, L., Sathicq, G., Pizzio, L., Romanelli, G., Blanco, M. 2017. Preaparation of Acetates Catalyzed by Boric Acid and/or Tungstophosphoric Acid-Modified Zirconia Obtained Employing Polyethylene Glycols as Pore-Forming Agents. Journal of Molecular Catalysis A: Chemical, 426, 88-96.

Sari MA, Y., Situngkir, M.D. 2016. Synthesis, Characterization, and Thermal Stability of $\mathrm{K} 8\left[\mathrm{SiW}_{11} \mathrm{O}_{39}\right] \mathrm{nH}_{2} \mathrm{O} / \mathrm{SiO}_{2}$. Science and Technology Indonesia, 1(1), 8-16. 